\title{
Socioeconomic status in relation to early menarche among black and white girls
}

\author{
Dejana Braithwaite - Dan H. Moore - Robert H. Lustig • \\ Elissa S. Epel · Ken K. Ong · David H. Rehkopf · \\ May C. Wang $\cdot$ Suzanne M. Miller $\cdot$ Robert A. Hiatt
}

Received: 31 March 2008/Accepted: 8 December 2008/Published online: 25 December 2008

(C) The Author(s) 2008. This article is published with open access at Springerlink.com

\begin{abstract}
Objective Early menarche is a risk factor for breast cancer. We investigated the variation in age at menarche by socioeconomic status (SES) and race.

Methods A cohort study was conducted on 1,091 black and 986 white girls from the three sites in the United States as part of the NHLBI Growth and Health Study (NGHS), who were aged 9-10 years at baseline and followed through adolescence over a 10-year period with annual exams. Using logistic regression models, we evaluated the nature and strength of associations between two socioeconomic indicators (household income and parental education) and early menarche ( $<12$ years old) unadjusted and adjusted for anthropometry and maternal age at menarche.

Results Proportionately, more black girls were menarcheal before 12 years of age compared to their white counterparts $(46 \%, n=468$ vs. $26 \%, n=240$, respectively, $p<0.0001)$. Parental education was not a significant predictor of early menarche. The graded
\end{abstract}

D. Braithwaite $(\bowtie) \cdot$ D. H. Moore $\cdot$ R. H. Lustig ·

E. S. Epel - D. H. Rehkopf - R. A. Hiatt

Department of Epidemiology and Biostatistics, Helen Diller

Family Comprehensive Cancer Center, University of California,

San Francisco, 185 Berry Street, Lobby 4 Suite 5700,

San Francisco, CA 94107, USA

e-mail: DBraithwaite@psg-ucsf.org

K. K. Ong

Medical Research Council Epidemiology Unit, Cambridge, UK

M. C. Wang

University of California, Berkeley, CA, USA

S. M. Miller

Fox Chase Cancer Center, Philadelphia, PA, USA association between household income and age at menarche was strong and significant among black girls but less clear among white girls. Compared with those in the lowest quartile of household income, white girls in the highest quartile were at a significantly lower risk of early menarche [adjusted odds ratio $(\mathrm{OR})=0.37,95 \%$ confidence intervals (CIs) 0.18-0.80]. The inverse was true for black girls: those in the highest quartile of household income were at an increased risk of early menarche (adjusted OR $=2.15$, 95\% CI 1.27-3.63)

Conclusion The SES factor selected (household income versus parental education) affected the findings regarding racial differences in the timing of menarche. It will be important for future studies to elucidate the link between household income and age at menarche in developed countries.

Keywords Socioeconomic status - Race/ethnicity · Early menarche $\cdot$ Breast cancer

\section{Introduction}

Age at menarche has been declining over the last two centuries in most parts of the world, and among the girls in the United States, there is evidence that it continues to do so [1]. In particular, black girls reach menarche earlier than their white counterparts and the ongoing rate of menarche decline appears to be faster among black girls [1-3]. Consistent with the life course theory, early life exposures may be important in programming the risk of cancer later in life $[4,5]$. Because early pubertal development and menarcheal activation are considered a critical window of vulnerability to breast carcinogenesis [6], secular trends toward early puberty are a major public health concern. 
These developments underscore the importance of examining this potentially modifiable risk factor for breast cancer in early life [7].

Among girls in the United States, recent epidemiologic evidence suggests that low socioeconomic status (SES) may be related to early puberty [8-10], as determined by entry into the stage 2 of breast development based on the staging system developed by Tanner and Whitehouse [11]. A comprehensive review published in 2003, however, reported inconsistent associations between socioeconomic circumstances and the onset of puberty: developed versus developing countries showed particularly marked variations [12]. Evidence also varies according to how SES was measured, in particular whether utilizing parental education or household income. For example, in one multiethnic cohort study, lower maternal education predicted early menarche but household income was unrelated [13]. More recently, studies have linked early puberty to both lower parental educational attainment [8-10] and lower household income [10, 14]. Methodological issues that may account for such inconsistencies in studies to date include cohort effects and variations in the sensitivity of SES indicators to different racial/ethnic groups.

Menarcheal activation is modulated by the hypothalamic-pituitary-gonadal system, particularly endogenous estradiol and lower sex hormone binding globulin $[15,16]$. In addition, menstrual onset occurs downstream of a cascade of endocrine changes including increased secretion of gonadotropin-releasing hormone $(\mathrm{GnRH})$, growth hormone (GH), and insulin [17, 18]. Because many predictors of age at menarche often covary with socioeconomic settings (e.g. anthropometric status, physical activity, family functioning), explanatory pathways remain poorly understood [19]. Efforts to identify the explanatory mechanisms are further complicated by the multidimensional nature of SES, since its relationship with outcome varies according to how it is measured [20]. What the aforementioned review [12] alludes to, nevertheless, is that some aspects of SES likely play a role in black-white differentials in the onset of menarche in the United States. Notably, such black-white differentials are not observed in the developing world: black African girls do not have a significantly increased risk of early puberty compared to their white African counterparts [21, 22].

In a prospective cohort study of black and white girls, who were followed with annual exams from the age of 9 or 10 through adolescence, we examined the association of two commonly used socioeconomic indicators-household income and parental education-with early menarche. A specific goal was to determine empirically whether the SES factor selected (household income or parental education) could affect the findings regarding racial/ethnic differences in the timing of menarche. Further, we sought to determine whether the relationship between SES and the onset of menarche can be explained by anthropometric factors [percentage fat by skinfolds, body fat distribution as indicated by the ratio between triceps skinfolds and the sum of subscapular and suprailiac skinfolds, body mass index (BMI), upper thigh circumference], caloric intake, physical activity, and aspects of the family environment.

\section{Methods}

Study design and population

The National Growth and Health Study is a cohort study of 2,379 girls $(1,213$ black and 1,166 white), aged 9 or 10 years at entry. The cohort was followed annually until ages 18-19 years. The present analysis focuses on baseline assessments of predictors of age at menarche. The study design, protocol, and baseline characteristics have been previously reported in detail elsewhere [23].

Participants were recruited by three clinical centers: University of California at Berkeley, University of Cincinnati/Cincinnati Children's Hospital Medical Center, and Westat, Inc./Group Health Association in Rockville, MD. Berkeley recruited participants from public and parochial schools in the Richmond Unified School District. That area was chosen based on census tract data showing approximately equal percentages of black and white children with the least degree of income and occupational disparity between the races. Cincinnati recruited participants from public and parochial schools in greater Cincinnati that were selected to be racially and socioeconomically representative of Hamilton County (which includes inner city, urban residential, and suburban areas). The cohort selected by Westat was randomly drawn from a membership listing of potentially eligible families who had girls aged 9 or 10 and who were enrolled in the prepaid medical program of Group Health Association, a large Washington, DC, area health maintenance organization.

The rationale for recruiting participants from three different geographical areas was to allow for a wide range of socioeconomic backgrounds and to reduce the chance of biased results due to local habits or local ancestry. To reduce the influence of cultural diversity, eligibility was restricted to girls living in racially concordant households and excluded Hispanics of either race or other ethnic groups. If a guardian was not the natural parent, investigators attempted to ascertain the race of the natural parent.

The Institutional Review Board approval for the present analyses was obtained from the University of California, San Francisco. The public release data set used in this study was obtained directly from the NHLBI. 
Study variables

All study variables, with the exception of girls' age at menarche, were collected at baseline (Y1 of the study).

\section{Definition of endpoints}

Age at menarche was assessed by a female research assistant during the annual examinations. Girls were asked whether their menstrual periods had started, and if so, to specify the date. Also, in subsequent annual exams, participants were asked retrospectively to recall age at menarche (expand). For the purposes of this analysis, age at menarche was estimated from the menarche onset date participants provided after the first affirmative response to the question regarding the onset of menses. Age at menarche was calculated from the date of birth to the date of the first menstrual period. Consistent with established cutoffs [4], early menarche was defined as $<12$ years, while average or late menarche was defined as 12 years or older. Reliability of self-reported age at menarche is well established [24].

\section{Definition of socioeconomic status}

Measures of SES obtained during the baseline interviews were used in the present analyses. Parents or guardians reported their highest educational level and household income. Efforts were made to interview both caregivers, but when this was not possible, the available parent (or legal guardian) was asked to report on their partner's education and income. If parents were educationally discordant, 'maximum parental education' was derived from the educational level of the parent with higher educational qualifications using a trichotomous scale ('high school or less,' 'some college,' and 'college or more'). To assess annual household income, a four-point scale was utilized ('less than \$9,999,' '\$10,000-29,999,' ‘30,000-39,999,' and ' $\geq \$ 40,000$ ').

\section{Covariates}

The following baseline covariates that were previously associated with age at menarche [19] were considered in the present analyses.

Anthropometric factors. Height, weight, and body fat measurements were taken from girls and parents by examiners who were centrally trained and certified as part of the study. Weight was measured using a Health-o-meter electronic scale (Model 482). Two weight measurements were obtained, and a third measurement was taken if the first two differed by more than $0.3 \mathrm{~kg}$. Using a custom portable stadiometer (Creative Health Products, Plymouth, Mich.), each girl's height was measured when she was in socks, with her heels together, toes apart at a $45^{\circ}$ angle, and head in the Frankfort horizontal plane. Two height measures were obtained with a third measure taken if the first two were more than $0.5 \mathrm{~cm}$ apart. Girth measurements were obtained at the upper thigh and at the upper arm, using a fiberglass tape. Although an imprecise measure of obesity, BMI was used in this study to estimate the prevalence of obesity and was calculated using the Quetelet index-weight $/$ height $^{2}$ (i.e., $\mathrm{kg} / \mathrm{m}^{2}$ ). BMI is moderately correlated with subscapular skinfolds and with percentage of body fat based on underwater weighting. Thus, NGHS used another independent measure of body composition suitable for population studies: skinfolds at three sites. This measure was obtained at the triceps (halfway between the acromion process and the olecranon process), suprailiac (about $20 \mathrm{~mm}$ above the iliac crest in the axillary line), and subscapular sites (about $20 \mathrm{~mm}$ below the tip of the scapula, at an angle of $45^{\circ}$ to the lateral side of the body) using Holtain calipers (Pfister Import-Export, Inc., Carlstadt, NJ). Skinfolds and girths were measured twice and repeated a third time if the first two measurements were discrepant by more than $1.0 \mathrm{~mm}$ and $0.5 \mathrm{~cm}$, respectively. The average of the two or the closest two of three measurements was used in data analysis. Girth and skinfold measurements and the estimation of percentage body fat were performed according to Cameron's method [25].

Caloric intake and physical activity. Girls completed a three-day food diary and a three-day physical activity diary (AD) at baseline. These measures were described in detail elsewhere [26, 27]. Both diaries included one weekend day and two weekdays. The completed food and activity diaries were reviewed by centrally trained and certified nutritionists at the Nutrition Coordinating Center at the University of Minnesota for the first two years and thereafter at the Dietary Data Entry Center at Cincinnati Children's Hospital, using the Nutrient Data System developed by the University of Minnesota. The NGHS dietary data collection method has been previously validated [26]. The estimation of daily activity levels was based on the sum of the recorded activities, which were scored with approximate metabolic equivalent (MET) levels and duration of the activity [27]. Coding and scoring of physical activity information were centrally coordinated by the Physical Activity Data Unit at the University of Pittsburgh.

Family discord. Assessment of psychosocial and environmental characteristics of families was conducted using a subset of seven items from the Family Environment Scale (FES, [28]), which measured girls' perceptions of their actual family environment ('In my family we feel closer to each other than to people outside the family,' 'In my family we like to spend free time with each other,' 'In my family we feel very close to each other,' 'When our family gets together for activities, everybody comes,' 'We can easily 
think of things to do together as a family,' 'In my family we ask other family members about our decisions,' 'In my family togetherness is very important.'). This scale has been used in diverse populations [28]. Questions were assessed on a four-point scale and then reverse scored, with higher levels representing more family discord. Items were then summed to develop a summary score for the subscale.

Family structure. Participants were asked to report on the number of parents and siblings in their household.

Maternal age at menarche (in years) was obtained by recall from mothers and modeled as a continuous variable.

\section{Statistical analysis}

Descriptive statistics, including subject characteristics by race, were evaluated using contingency table analyses, the $\chi^{2}$ test for trend in proportions and $t$-test for comparison of groups on the continuous data. Modeling progressed from univariate to multivariate, guided by a priori considerations [29]. Multicollinearity among the explanatory variables was examined. Logistic regression analyses were performed to estimate odds ratios (ORs) and 95\% confidence intervals (CIs) for the association between the predictors (SES, anthropometric factors, caloric intake, physical activity, maternal age at menarche, family structure, and family discord) and the timing of menarche onset. Household income and parental education were modeled as both polytomous and ordered categorical variables, and the ORs $(95 \% \mathrm{CI})$ for levels of income and education $(1,2$, $3+$ ) were estimated in relation to the group with the lowest income and education. Interactions between race and SES were evaluated. Race-specific models were estimated to evaluate the extent to which results differed by this variable. The $\alpha$ error was set at 0.05 and all reported $p$-values are two-sided. Analyses were performed using Intercooled STATA 9.0 for Windows (Stata Corporation, College Station, TX).

\section{Results}

\section{Study characteristics}

The present analyses included 1,091 black and 986 white girls, who provided information on age at menarche. Of the small number of girls who were menarcheal at baseline, $0.01 \%$ were white $(n=10)$ and $3 \%$ were black $(n=30)$. As shown in Fig. 1, age at menarche was normally distributed in both groups and ranged from 8 to 17 years. Further, proportionately more black girls were menarcheal before 12 years of age compared to their white counterparts $(46 \%, n=468$ vs. $26 \%, n=240$, respectively, $p<0.0001$, Fig. 1).
The most complex multivariate model including household income, parental education, anthropometric factors (percentage fat by skinfolds, body fat distribution as indicated by the ratio between triceps skinfolds and the sum of subscapular and suprailiac skinfolds, BMI, upper thigh circumference), caloric intake, physical activity, maternal age at menarche, family discord, and family structure as predictors of age at menarche was based on $657(65 \%)$ blacks and $669(72 \%)$ whites.

The distribution of baseline characteristics by race is presented in Table 1 . Black girls were significantly taller and heavier (all $p<0.0001$ ). Proportionately, more black girls than their white counterparts had lower parental educational attainment: $30.1 \%(n=307)$ vs. $20.1 \%$ $(n=189)$, respectively $(p<0.0001)$. In addition, proportionately more blacks than whites were poor, as defined by household income below \$9,999: $26.7 \%(n=272)$ vs. $7.6 \%(n=71), p<0.0001$. It is notable that household income and parental education were more strongly correlated among white girls than among their black counterparts (Spearman's rank correlation coefficients were 0.51 vs. 0.43 , respectively). Black girls were also significantly more likely to be less physically active $(p<0.0001)$, to have higher caloric intake $(p<0.0001)$, and to live in more adverse family environments (as indicated by the FES subscale; $p=0.003$ ).

\section{Univariate predictors of early menarche}

Table 1 shows univariate logistic regression ORs and 95\% CIs between study variables and early menarche. Parental education was not associated with early menarche $(\mathrm{OR}=0.81,95 \%$ CI $0.64-1.02$ among white girls and $\mathrm{OR}=0.91,95 \%$ CI $0.72-1.15$ among black girls). In contrast, there was a statistically significant association of lower household income with early menarche among white girls $(\mathrm{OR}=0.74,95 \%$ CI $0.61-0.91)$. The reverse was true among black girls: there was a significant relationship between higher household income and early menarche $(\mathrm{OR}=1.20$, 95\% CI 1.03-1.41). We next examined anthropometric factors and found an association between higher BMI and early menarche among both white girls $(\mathrm{OR}=1.15, \quad 95 \% \quad \mathrm{CI} \quad 1.09-1.22)$ and black girls $(\mathrm{OR}=1.13,95 \%$ CI 1.08-1.18). Other significant anthropometric predictors of early menarche were percentage fat by skinfolds $(\mathrm{OR}=1.05,95 \%$ CI $1.03-1.07$ among white girls versus $\mathrm{OR}=1.03,95 \%$ CI $1.02-1.04$ among black girls), upper thigh circumference $(\mathrm{OR}=1.10,95 \% \mathrm{CI}$ $1.08-1.13$ among white girls versus $\mathrm{OR}=1.07,95 \% \mathrm{CI}$ 1.05-1.09 among black girls), and body fat distribution as indicated by the ratio between triceps skinfolds and the sum of subscapular and suprailiac skinfolds $(\mathrm{OR}=0.17,95 \% \mathrm{CI}$ $0.09-0.35$ among white girls versus $\mathrm{OR}=0.20,95 \%$ CI 
Fig. 1 Distribution of age at menarche by race. Vertical bars show mean ages at menarche (white girls, mean $=12.7$ years; black girls, mean $=12.1$ years)

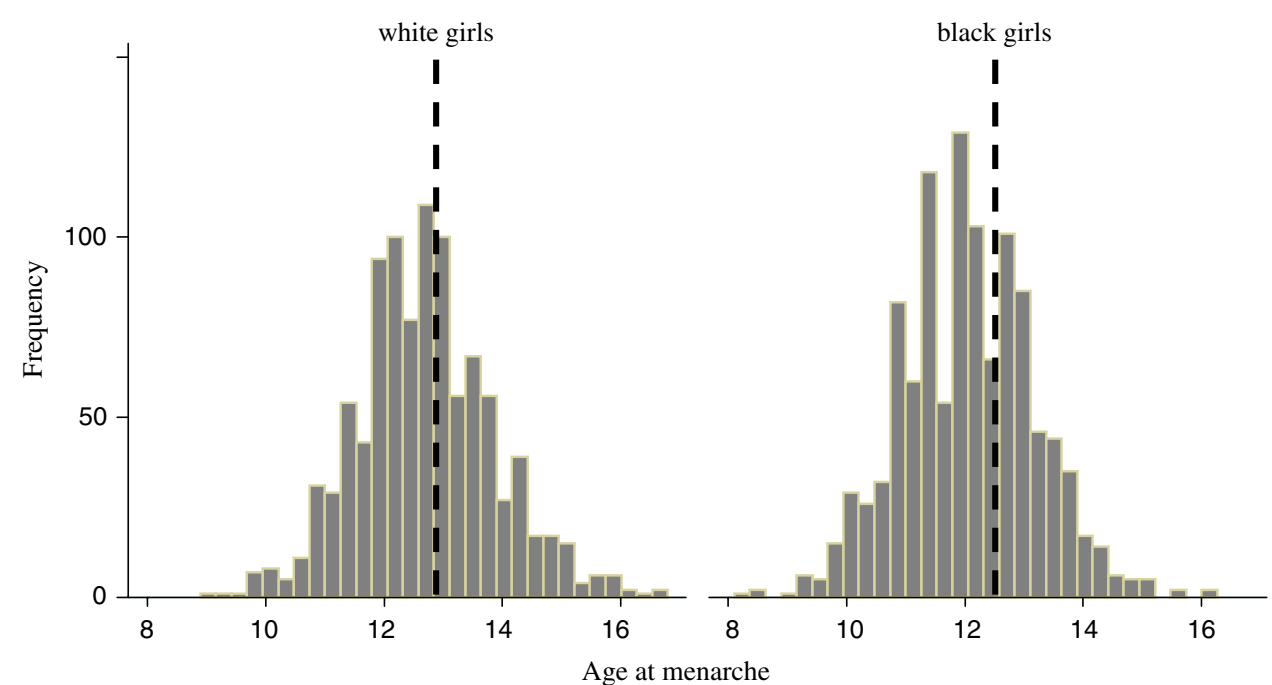

0.10-0.42 among black girls). In addition, higher maternal age at menarche (as indicated by a continuous variable) was protective against early menarche among both white girls $(\mathrm{OR}=0.75,95 \% \mathrm{CI} 0.65-0.85)$ and their black counterparts $(\mathrm{OR}=0.80,95 \% \mathrm{CI} 0.73-0.88)$. Further, measures of caloric intake, physical activity, and the family environment were not significantly related to early menarche in either racial group.

Race, socioeconomic status, and early menarche

Being black was associated with early menarche $(\mathrm{OR}=2.42,95 \%$ CI 2.01-2.92). After household income was taken into account, the OR was 2.46 (95\% CI 2.013.02). When parental education was controlled, the estimate did not change significantly ( $\mathrm{OR}=2.33,95 \% \mathrm{CI}$ 1.92-2.82). While the effect of one SES indicatorhousehold income-on the timing of menarche differed between black and white girls as reflected by a significant interaction between household income and race ( $p<0.0001$, Table 2$)$, the interaction was not significant with the other SES indicator-parental education (Table 3).

Tables 2 and 3 show estimates of associations between socioeconomic factors and early menarche unadjusted and adjusted for covariates that were positively associated with outcome in univariate analyses: percentage fat by skinfolds, body fat distribution as indicated by the ratio between triceps skinfolds and the sum of subscapular and suprailiac skinfolds, BMI, upper thigh circumference, and maternal age at menarche. In addition, when household income was modeled, we adjusted for parental education, and conversely, modeling the predictive value of parental education meant controlling for household income. White girls in the highest quartile of household income were at a significantly lower risk of early menarche after taking covariates into consideration $(\mathrm{OR}=0.37,95 \%$ CI 0.18 0.80). In addition, the inverse pattern was observed among black girls: those in the highest quartile of household income were at an increased risk of early menarche compared to the lowest income quartile (adjusted OR $=2.15$, 95\% CI 1.27-3.63, Table 2). As shown in Table 3, parental education was not associated with early menarche among the girls in the present study. Notably, when adjusted models were extended to include caloric intake, physical activity, number of parents and siblings, and the family environment subscale, no significant changes in estimates in any of the models were observed (data not shown).

\section{Discussion}

In the present study, nearly half of black girls were menarcheal before 12 years of age compared to approximately a quarter of their white counterparts. Overall, parental education was unrelated to age at menarche in the present cohort. The novel finding of this study is that the graded association between household income and age at menarche was strong and significant among black girls but less clear among white girls. Specifically, while higher levels of household income were protective against early menarche among white girls (adjusted OR approximately 0.40 for the highest socioeconomic stratum), the opposite was true for black girls who were more likely to go through early menarche at higher levels of household income (adjusted OR 2.15 for the highest stratum). This pattern of findings among black girls is more akin to that of developing countries where higher SES has been linked with early menarche [12], presumably due to nutrition-related factors.

While a positive association between household income and age at menarche is consistent with at least two other 
Table 1 Study variables by race and univariate logistic regression odds ratios (ORs) and (95\% CI) with early menarche ( $<12$ years)

\begin{tabular}{|c|c|c|c|c|c|c|}
\hline Predictor variable & $\begin{array}{l}\text { White } \\
\%, n\end{array}$ & $\begin{array}{l}\text { Black } \\
\%, n\end{array}$ & $\begin{array}{l}\text { Black } \\
\text { white }\end{array}$ & rsus & $\begin{array}{l}\text { White } \\
\text { OR (95\% CI) }\end{array}$ & $\begin{array}{l}\text { Black } \\
\text { OR }(95 \% \text { CI })\end{array}$ \\
\hline \multicolumn{3}{|l|}{ Parental education } & \multicolumn{2}{|c|}{$<0.0001$} & $0.81(0.64-1.02)^{\mathrm{b}}$ & \multirow[t]{4}{*}{$0.91(0.72-1.15)^{\mathrm{b}}$} \\
\hline High school or less & $20.1,189$ & $30.1,307$ & & & & \\
\hline 1-3 years post-high school & $30.1,283$ & $48.6,495$ & & & & \\
\hline College or more & $49.7,467$ & $21.3,217$ & & & & \\
\hline \multicolumn{3}{|l|}{ Household income } & \multicolumn{2}{|c|}{$<0.0001$} & $0.74(0.61-.91)^{\mathrm{c}}$ & \multirow[t]{5}{*}{$1.20(1.03-1.41)^{\mathrm{c}}$} \\
\hline$<\$ 9,999$ & $7.6,71$ & $26.7,272$ & & & & \\
\hline$\$ 10,000-29,999$ & $9.8,92$ & $18.8,192$ & & & & \\
\hline$\$ 30,000-39,999$ & $32.2,302$ & $29.9,305$ & & & & \\
\hline$\$ 40,000+$ & $50.5,474$ & $24.5,250$ & & & & \\
\hline \multicolumn{7}{|l|}{ Number of parents } \\
\hline 1 & $18.9,220$ & $43.7,530$ & \multirow{2}{*}{\multicolumn{2}{|c|}{$<0.0001$}} & \multirow[t]{2}{*}{$0.80(0.56-1.14)$} & \multirow[t]{2}{*}{$1.17(0.92-1.49)$} \\
\hline 2 & $81.1,945$ & $56.3,683$ & & & & \\
\hline Predictor variable & $\begin{array}{l}\text { White } \\
\text { Mean, SD, } n\end{array}$ & \multicolumn{2}{|c|}{$\begin{array}{l}\text { Black } \\
\text { Mean, SD, } n\end{array}$} & $\begin{array}{l}\text { Black versus } \\
\text { white } P^{\mathrm{a}}\end{array}$ & $\begin{array}{l}\text { White } \\
\text { OR }(95 \% \text { CI })\end{array}$ & $\begin{array}{l}\text { Black } \\
\text { OR (95\% CI) }\end{array}$ \\
\hline Number of siblings & $1.5,1.2,1165$ & \multicolumn{2}{|c|}{$1.5,1.3,1213$} & 0.81 & $0.82(0.69-0.97)$ & $0.94(0.86-1.04)$ \\
\hline Height $(\mathrm{cm})$ & $139.6,7.1,1159$ & \multicolumn{2}{|c|}{$142.9,7.9,1201$} & $<0.0001$ & $1.08(1.06-1.11)$ & $1.11(1.09-1.13)$ \\
\hline Weight (kg) & $35.4,8.7,1158$ & \multicolumn{2}{|c|}{$39.6,11.2,1203$} & $<0.0001$ & $1.07(1.05-1.09)$ & $1.06(1.05-1.07)$ \\
\hline Body mass index & $18.0,3.3,1158$ & \multicolumn{2}{|c|}{$19.2,4.2,1201$} & $<0.0001$ & $1.15(1.09-1.22)$ & $1.13(1.08-1.18)$ \\
\hline Percent fat by skinfolds & $20.8,7.5,1154$ & \multicolumn{2}{|c|}{$21.5,9.1,1202$} & 0.02 & $1.05(1.03-1.07)$ & $1.03(1.02-1.04)$ \\
\hline Upper thigh circumference $(\mathrm{cm})$ & $45.4,6.0,1156$ & \multicolumn{2}{|c|}{$48.3,7.8,1203$} & $<0.0001$ & $1.10(1.08-1.13)$ & $1.07(1.05-1.09)$ \\
\hline $\begin{array}{l}\text { Ratio between triceps skinfolds } \\
\text { and the sum of subscapular } \\
\text { and suprailiac skinfolds }\end{array}$ & $0.8,0.2,1150$ & \multicolumn{2}{|c|}{$0.7,0.2,1199$} & $<0.0001$ & $0.17(0.09-0.35)$ & $0.20(0.10-0.42)$ \\
\hline MET hour physical activity & $538.1,413.0,1090$ & \multicolumn{2}{|c|}{$629.0,570.8,988$} & $<0.0001$ & $1.00(1.00-1.01)$ & $1.00(1.00-1.01)$ \\
\hline Caloric intake (kcal) & $1767.7,560.5,1005$ & \multicolumn{2}{|c|}{$1952.1,735.4,989$} & $<0.0001$ & $1.00(0.99-1.00)$ & $1.00(0.99-1.00)$ \\
\hline Family discord & $2.9,0.5,1149$ & \multicolumn{2}{|c|}{$3.0,0.6,1194$} & 0.001 & $0.84(0.62-1.13)$ & $0.91(0.73-1.14)$ \\
\hline Maternal age at menarche & $12.5,1.5,847$ & \multicolumn{2}{|c|}{$12.4,1.7,762$} & 0.64 & $0.75(0.65-0.85)$ & $0.80(0.73-0.88)$ \\
\hline
\end{tabular}

All measures were taken at baseline when girls were 9 or 10 years old, with the exception of maternal age at menarche, which was assessed during subsequent visits also. Higher values on family discord as indicated by the Family Environment subscale indicate more discord

${ }^{a}$ Difference, ${ }^{b}$ Highest tertile compared to the lowest, ${ }^{c}$ Highest quartile compared to the lowest

studies $[8,10]$, the lack of statistically significant influences of parental education on this outcome in the present study contrasts some previous reports [9, 13]. This may perhaps be due to the fact that parental education has been measured inconsistently (maternal educational attainment only versus maximum educational attainment of both parents/guardians). Thus, as we hypothesized, the SES factor selected (household income versus parental education) affected the findings regarding racial/ethnic differences in the timing of menarche. Since components of SES have different meanings in certain racial/ethnic groups [20], it is important to go beyond household income and parental education when elucidating socioeconomic risk factors for early puberty [20]. Indeed, there is evidence that at the same income levels, wealth and debt are independent predictors of racial/ethnic disparities in health outcomes [30, 31].

As a secondary goal, we attempted to determine the pathways by which socioeconomic characteristics affect age at menarche. SES represents proxies for other risk factors [32], and likely underlies at least two proximal determinants of the onset of puberty: anthropometric factors and environmental exposure (e.g., toxic agents, residential crowding) [33]. With regard to anthropometry, recent longitudinal studies have consistently indicated that adiposity in early childhood predicts early puberty $[8,9]$. The gain in body fat may be one of the key signals, possibly through secretion of the fat-derived protein leptin, for stimulating the hypothalamus to increase secretion of GnRH [34], which in turn stimulates the pituitary-ovarian 
Table 2 Univariate and multivariate logistic regression odds ratios (95\% CI) between income strata and early menarche $(<12$ years)

\begin{tabular}{|c|c|c|c|c|c|}
\hline \multirow[t]{2}{*}{ Race } & \multicolumn{4}{|c|}{ Income strata } & \multirow[t]{2}{*}{ Race $\times$ income interaction } \\
\hline & $\leq \$ 9,999^{\mathrm{c}}$ & $\$ 10,000-19,999$ & $\$ 20,000-39,999$ & $\geq \$ 40,000$ & \\
\hline White & $(n=71)$ & $(n=92)$ & $(n=302)$ & $(n=474)$ & \multirow{6}{*}{$\begin{array}{l}\text { Unadjusted OR }=1.50 \\
\quad(95 \% \text { CI } 1.24-1.81, p<0.0001) \\
\text { Adjusted } \text { OR }^{\mathrm{a}}=1.58 \\
\quad(95 \% \text { CI } 1.23-2.03, p<0.0001)\end{array}$} \\
\hline Unadjusted OR (95\% CI) & 1.00 & $0.49(0.20-1.21)$ & $0.58(0.28-1.17)$ & $0.37(0.18-0.73)$ & \\
\hline Adjusted $\mathrm{OR}^{\mathrm{a}, \mathrm{b}}(95 \% \mathrm{CI})$ & 1.00 & $0.41(0.17-1.01)$ & $0.57(0.27-1.17)$ & $0.37(0.18-0.80)$ & \\
\hline Black & $(n=272)$ & $(n=192)$ & $(n=305)$ & $(n=250)$ & \\
\hline Unadjusted OR (95\% CI) & 1.00 & $1.69(0.96-2.99)$ & $2.17(1.33-3.53)$ & $1.79(1.09-2.94)$ & \\
\hline Adjusted $\mathrm{OR}^{\mathrm{a}, \mathrm{b}}(95 \% \mathrm{CI})$ & 1.00 & $1.96(1.16-3.31)$ & $2.44(1.50-3.96)$ & $2.15(1.27-3.63)$ & \\
\hline
\end{tabular}

a Adjusted for parental education, percentage fat based on skinfolds, body fat distribution (as indicated by the ratio between triceps skinfolds and the sum of subscapular and suprailiac skinfolds), body mass index, upper thigh circumference, and maternal age at menarche

b Additional adjustment for caloric intake, physical activity, number of parents and siblings, and the family environment subscale did not result in significant changes in estimates

${ }^{c}$ Referent

Table 3 Univariate and multivariate logistic regression odds ratios $(95 \% \mathrm{CI})$ between education strata and early menarche $(<12$ years)

\begin{tabular}{|c|c|c|c|c|}
\hline \multirow[t]{2}{*}{ Race } & \multicolumn{3}{|l|}{ Education strata } & \multirow[t]{2}{*}{ Race $\times$ education interaction } \\
\hline & High school or less ${ }^{c}$ & Some college & College or more & \\
\hline White & $(n=189)$ & $(n=283)$ & $(n=467)$ & \multirow{6}{*}{$\begin{array}{l}\text { Unadjusted OR }=1.12 \\
\quad(95 \% \text { CI } 0.80-1.56, p=0.50) \\
\text { Adjusted OR }=1.10 \\
\quad(95 \% \text { CI } 0.78-1.54, p=0.94)\end{array}$} \\
\hline Unadjusted OR (95\% CI) & 1.00 & $0.74(0.44-1.25)$ & $0.64(0.40-1.04)$ & \\
\hline Adjusted $\mathrm{OR}^{\mathrm{a}, \mathrm{b}}(95 \% \mathrm{CI})$ & 1.00 & $1.00(0.58-1.73)$ & $1.02(0.57-1.81)$ & \\
\hline Black & $(n=307)$ & $(n=495)$ & $(n=217)$ & \\
\hline Unadjusted OR (95\% CI) & 1.00 & $0.85(0.56-1.29)$ & $0.83(0.51-1.33)$ & \\
\hline Adjusted $\mathrm{OR}^{\mathrm{a}, \mathrm{b}}(95 \% \mathrm{CI})$ & 1.00 & $0.67(0.44-1.02)$ & $0.63(0.37-1.07)$ & \\
\hline
\end{tabular}

${ }^{a}$ Adjusted for household income, percentage fat based on skinfolds, body fat distribution (as indicated by the ratio between triceps skinfolds and the sum of subscapular and suprailiac skinfolds), body mass index, upper thigh circumference, and maternal age at menarche

b Additional adjustment for caloric intake, physical activity, and family environment did not result in significant changes in estimates

c Referent

axis and initiates the pubertal cascade. In the present study, several anthropometric factors (upper thigh circumference, BMI, percent body fat, body fat distribution) were positively associated with age at menarche. Other potential mediating variables such as caloric intake, MET hour physical activity, and the family environment were unrelated to age at menarche in univariate analyses. Our findings indicate that these factors did not fully explain the association between household income and age at menarche in multivariate models. Further complicating the picture was the finding that BMI, while consistently associated with SES among white girls, was unrelated to SES among their black counterparts in the NGHS study [35].

The current study has several design strengths, but also some notable limitations. It included a large cohort of black and white girls from three study sites with long follow-up. We were able to evaluate, both cross-sectionally and longitudinally, the contribution of socioeconomic factors to girls' menses onset. However, specific data on socioeconomic indicators and covariates prior to the participants' study entry at age 9 or 10 were not available and, therefore, were not evaluated in our analysis. While we were able to adjust for a number of potential explanatory variables linking SES and menarche, including anthropometric factors, we were unable to probe exposure to hormonally active environmental agents [36] as potential mediators of the association between SES and age at menarche.

In conclusion, our findings show that nearly half of black girls were menarcheal before 12 years of age compared to approximately a quarter of their white counterparts. Compared with those in the lowest income quartile, white girls in the top quartile of household income were at significantly lower risk of early menarche after taking into account maternal age at menarche, parental educational attainment, and anthropometry. The inverse was true for black girls, with those in the highest income quartile showing a higher prevalence of early menarche. If contemporary cohort studies of economically diverse girls confirmed the relevance of household income resources for pubertal timing and were also able to include a wider array of potential mediating variables (e.g., energy balance health behaviors, exposure to hormonally active agents), 
the resulting information may generate important insights into the pathways leading to the social patterning of pubertal development.

Acknowledgments We gratefully acknowledge the support of the Prevent Cancer Foundation/American Society for Preventive Oncology (Cancer Prevention Fellowship 2007-2009; PI Dr. Dejana Braithwaite). Statistical analyses were performed using a limited access dataset obtained from the NHLBI.

Open Access This article is distributed under the terms of the Creative Commons Attribution Noncommercial License which permits any noncommercial use, distribution, and reproduction in any medium, provided the original author(s) and source are credited.

\section{References}

1. Anderson SE, Dallal GE, Must A (2003) Relative weight and race influence average age at menarche: results from two nationally representative surveys of US girls studied 25 years apart. Pediatrics 111:844-850

2. Chumlea WC, Schubert CM, Roche AF, Kulin HE, Lee PA, Himes JH, Sun SS (2003) Age at menarche and racial comparisons in US girls. Pediatrics 111:110-113

3. Wattigney WA, Srinivasan SR, Chen W, Greenlund KJ, Berenson GS (1999) Secular trend of earlier onset of menarche with increasing obesity in black and white girls: the Bogalusa Heart Study. Ethn Dis 9:181-189

4. Forman MR, Cantwell MM, Ronckers C, Zhang Y (2005) Through the looking glass at early-life exposures and breast cancer risk. Cancer Invest 23:609-624

5. Mona O, Peter M, David G, George Davey S (2003) Exposures in childhood, adolescence and early adulthood and breast cancer risk: a systematic review of the literature. Breast Cancer Res Treat V78:223

6. Kelsey JL, Gammon MD (1990) Epidemiology of breast cancer. Epidemiol Rev 12:228-240

7. Colditz GA, Frazier AL (1995) Models of breast cancer show that risk is set by events of early life: prevention efforts must shift focus. Cancer Epidemiol Biomarkers Prev 4:567-571

8. Davison KK, Susman EJ, Birch LL (2003) Percent body fat at age 5 predicts earlier pubertal development among girls at age 9 . Pediatrics 111:815-821

9. Lee JM, Appugliese D, Kaciroti N, Corwyn RF, Bradley RH, Lumeng JC (2007) Weight status in young girls and the onset of puberty. Pediatrics 119:E624-E630

10. Ellis BJ, Essex MJ (2007) Family environments, adrenarche, and sexual maturation: a longitudinal test of a life history model. Child Dev 78:1799-1817

11. Tanner JM, Whitehouse RH (1976) Clinical longitudinal standards for height, weight, height velocity, weight velocity, and stages of puberty. Arch Dis Child 51:170-179

12. Parent AS, Teilmann G, Juul A, Skakkebaek NE, Toppari J, Bourguignon JP (2003) The timing of normal puberty and the age limits of sexual precocity: variations around the world, secular trends, and changes after migration. Endocr Rev 24:668-693

13. Windham GC, Bottomley C, Birner C, Fenster L (2004) Age at menarche in relation to maternal use of tobacco, alcohol, coffee, and tea during pregnancy. Am J Epidemiol 159:862-871

14. Davison KK, Marshall SJ, Birch LL (2006) Cross-sectional and longitudinal associations between TV viewing and girls' body mass index, overweight status, and percentage of body fat. J Pediatr 149:32-37
15. Vihko R, Apter D (1984) Endocrine characteristics of adolescent menstrual cycles: Impact of early menarche. J Steroid Biochem 20:231

16. Apter D, Bolton NJ, Hammond GL, Vihko R (1984) Serum sex hormone-binding globulin during puberty in girls and in different types of adolescent menstrual cycles. Acta Endocrinol (Copenh) 107:413-419

17. Stoll BA, Vatten LJ, Kvinnsland S (1994) Does early physical maturity influence breast cancer risk? Acta Oncol 33:171-176

18. Stoll BA (1998) Western diet, early puberty, and breast cancer risk. Breast Cancer Res Treat 49:187-193

19. Ellis BJ (2004) Timing of pubertal maturation in girls: an integrated life history approach. Psychol Bull 130:920-958

20. Braveman PA, Cubbin C, Egerter S, Chideya S, Marchi KS, Metzler M, Posner S (2005) Socioeconomic status in health research: one size does not fit all. JAMA 294:2879-2888

21. Cameron N, Wright CA (1990) The start of breast development and age at menarche in South African black females. S Afr Med J 78:536-539

22. Fakeye O, Fagbule D (1990) Age and anthropometric status of Nigerian girls at puberty: implication for the introduction of sex education into secondary schools. West Afr J Med 9:226-231

23. Obesity and cardiovascular disease risk factors in black and white girls: the NHLBI Growth and Health Study (1992) Am J Public Health 82:1613-1620

24. Koo MM, Rohan TE (1997) Accuracy of short-term recall of age at menarche. Ann Hum Biol 24:61-64

25. Cameron N (1984) The measurement of human growth. Croom Helm, Beckenham

26. Crawford PB, Obarzanek E, Morrison J, Sabry ZI (1994) Comparative advantage of 3-day food records over 24-hour recall and 5-day food frequency validated by observation of 9- and 10-yearold girls. J Am Diet Assoc 94:626-630

27. Kimm SY, Glynn NW, Kriska AM, Fitzgerald SL, Aaron DJ, Similo SL, McMahon RP, Barton BA (2000) Longitudinal changes in physical activity in a biracial cohort during adolescence. Med Sci Sports Exerc 32:1445-1454

28. Moos RH (1990) Conceptual and empirical approaches to developing family-based assessment procedures: resolving the case of the Family Environment Scale. Fam Process 29:199-208; discussion 209-211

29. Greenland S (1989) Modeling and variable selection in epidemiologic analysis. Am J Public Health 79:340-349

30. Drentea P, Lavrakas PJ (2000) Over the limit: the association among health, race and debt. Soc Sci Med 50:517-529

31. Conley D (1999) Race, wealth and social policy in America. University of California Press, Berkeley

32. Angell M (1993) Privilege and health-what is the connection? N Engl J Med 329:126-127

33. Adler NE, Newman K (2002) Socioeconomic disparities in health: pathways and policies. Health Aff (Millwood) 21:60-76

34. Wilson ME, Fisher J, Chikazawa K, Yoda R, Legendre A, Mook D, Gould KG (2003) Leptin administration increases nocturnal concentrations of luteinizing hormone and growth hormone in juvenile female rhesus monkeys. J Clin Endocrinol Metab 88:4874-4883

35. Kimm SYS, Obarzanek E, Barton BA, Aston CE, Similo SL, Morrison JA, Sabry ZI, Schreiber GB, McMahon RP (1996) Race, socioeconomic status, and obesity in 9- to 10-year-old girls: the NHLBI Growth and Health Study. Ann Epidemiol 6:266-275

36. Wolff MS, Teitelbaum SL, Windham G, Pinney SM, Britton JA, Chelimo C, Godbold J, Biro F, Kushi LH, Pfeiffer CM, Calafat AM (2007) Pilot study of urinary biomarkers of phytoestrogens, phthalates, and phenols in girls. Environ Health Perspect 115:116-121 